\title{
A prognostic classification of cerebral cysticercosis: therapeutic implications
}

\author{
BRUNO ESTAÑOL, TERESA CORONA, PATRICIO ABAD \\ From the Neurology Service, Hospital General Centro Médico Nacional Cuauhtémoc, México
}

SUMMARY Cerebral cysticercosis is a parasitic infestation with a highly variable prognosis and diverse clinical manifestations. Over the period of two years 51 patients were studied prospectively with this infestation, paying particular attention to the duration and severity of the illness, clinical course, CT findings and therapeutic modalities. Patients with parenchymal cysts or calcification without hydrocephalus had a benign disorder presenting commonly with seizures. This type of infestation usually is long-standing, almost never requires surgical treatment, responds to praziquantel therapy and has a good prognosis. In contrast, patients who present with hydrocephalus, large supratentorial cysts, multiple granulomata with cerebral oedema or with vasculitis and cerebral infarction, have an aggressive, acute or subacute illness, presenting with raised intracranial pressure, gait disturbances, mental changes, seizures, cranial nerve palsies, hemisphere syndromes, chronic meningitis and stroke. This malignant form usually requires surgical therapy, does not respond to praziquantel and may produce a fatal outcome or serious sequelae.

Cerebral cysticercosis is a complex and heterogeneous infestation of the central nervous system with a highly variable prognosis and diverse clinical manifestations. In India, where this parasite is endemic it has long been known that cerebral cysticercosis may either be "silent" or it may cause the death of some patients. ${ }^{12}$ In Mexico in large necropsy series performed in the city of Mexico ${ }^{34}$ it has been found that approximately $3 \%$ of the population in which a postmortem study is carried out has cerebral cysticercosis. This appalling figure, however, is tempered by the fact that nearly $80 \%$ of the patients were asymptomatic during life, the infestation being a fortuitous or incidental necropsy finding. ${ }^{34}$ What is the reason for this highly variable pathogenic capacity of the parasite? It has been known for a number of years that round cysts of the Cysticercus cellulosae type located in the brain parenchyma or in the subarachnoid space of the convexity of the cerebral hemispheres do not induce marked inflammatory reaction. ${ }^{23}$ In contradistinction, patients with Cysticercus racemosus located in the subarachnoid space of the basal cysterns, usually develop an intense chronic inflammatory reaction frequently inducing chronic

Address for reprint requests: Bruno Estañol, M.D. Hospital Santelena, Querétaro 58, Col. Roma 06700, México 7, D.F. Mexico.

Received 28 November 1985 and in revised form 31 December 1985. Accepted 5 January 1986 meningitis, vasculitis, cranial nerve and brain stem damage. $^{34}$ Gardner et al have recently published the natural history of parenchymal cysticercosis as observed in 73 patients living in Los Angeles, California, during a 10 year period. They found that parenchymal cerebral cysticercosis was a relatively benign disease: $19 \%$ of the cases were diagnosed serendipitously. The main clinical problems were seizures $(80 \%$ of the cases). Only $6 \%$ required surgery and then just for diagnostic purposes. In most cases the infestation seemed to be compatible with normal life and work. ${ }^{1}$ In accord with these clinical results, it has been shown that most patients who were found to have cysticerci in the brain at necropsy but were asymptomatic during lifetime, had parenchymal cysts, calcification or a combination of both. ${ }^{4}$ On the other hand, the $20 \%$ of the patients in whom the cerebral cysticercosis was directly responsible of the demise of the patients, all had hydrocephalus. Thus, patients with hydrocephalus secondary to cerebral cysticercosis seem to have a malignant disease that may lead to an early death whereas parenchymal cysticercosis without hydrocephalus may be a relatively benign disease that either may be asymptomatic or present with seizures as the sole manifestation of infestation. The purpose of this study is to investigate in a selected population of 51 patients with cerebral cysticercosis the type of cerebral infestation and correlate the CT findings with the duration and severity 
of the illness, clinical course and therapeutic responses. This was a prospective study in which we followed the patients during a time period of two years.

\section{Patients and methods}

We studied 51 selected patients with cerebral cysticercosis during a time period of two years. The mean age of the patients was 40 years with a range between 18 and 62 years. The patients were selected on the basis of having proven cerebral cysticercosis either by direct visualisation of the parasite during surgery or by the presence of a distinct image of a parasite in the CT scan. The patients underwent a complete physical examination, chest radiography, CBC, SMA 12, urinalysis, EEG, skull radiography, lumbar puncture and CT scan. The CT was performed at least three times during the period of follow up. We quantitated the duration of the illness prior to the admission, performed a complete neurological examination, determined the initial symptoms, the presence or absence of raised intracranial pressure, mental changes, cranial nerve palsies, history of generalised or partial seizures and stroke. The presence or absence of inflammatory cells in the CSF was also assessed. A radioisotope cysternography was performed in the patients with hydrocephalus as described elsewhere. ${ }^{6}$ In the cases in which an intraventricular cyst was suspected metrizamide or conray 60 was introduced through the antechamber of the shunting device as described previously. ${ }^{6}$ Anticisticercous antibodies were detected in the serum CSF of all the patients by the ELISA method as described in a previous paper. ${ }^{11}$

\section{Results}

We found 20 patients who had a benign course with a long-standing illness of 5 years duration (range 1 to 9 years). These patients had parenchymal cysts $(45 \%)$, calcified parasites $(10 \%)$, a combination of parenchymal cysts and calcified parasites $(15 \%)$, isolated granuloma without oedema $(10 \%)$, and a combination of parenchymal cysts and isolated granuloma $(20 \%)$. (table 1). These patients were either asymptomatic, had partial seizures or headache. In at least five cases the headache was of a vascular type and appeared to be unrelated to the presence of the parasites. None of the patients required a surgical procedure. None of the patients had hydrocephalus, signs of vasculitis or cerebral infarction, and they had no inflammatory cells in the CSF. Only in $70 \%$ of the cases, anticisticerous antibodies were detected in the serum by the ELISA methods. In the CSF in $80 \%$ of the cases anticysticercous antibodies were detected by the ELISA method. The EEG was normal or detected only mild abnormalities ( $40 \%$ of the cases). The sixteen patients who had parenchymal cysts received praziquantel $50 \mathrm{mg} / \mathrm{kg}$. In two weeks this therapy induced the disappearance of $90 \%$ of the cysts.

We found 31 patients who had an aggressive illness that had a mean duration of six months (range 1 to 15 months). These patients had hydrocephalus ( $83 \%$ of the cases). The hydrocephalus was due to basal arachnoiditis (proven by isotope cisternography and CSF studies) in $48.3 \%$ of the cases. In $35.4 \%$ the hydrocephalus was due to intraventricular cysts (proven by ventriculography by CT). Three patients $(9 \cdot 6 \%)$ had large supratentorial cysts which induced a mass effect with displacement of the supratentorial ventricular system. One patient had multiple granulomata surrounded by oedema (cysticerus encephalitis). One patient had cerebral vasculitis and cerebral infarction (table 2). These patients had raised intracranial pressure, gait difficulties, mental changes, hemisphere syndromes, cranial nerve palsies, chronic meningitis, seizures, diffuse encephalopathy and stroke. The illness was frequently acute or subacute presenting most commonly with symptoms of increased intracranial pressure. The 26 patients who had hydrocephalus required a ventriculo-peritoneal shunt. Sixty per cent of the cases required at least two shunting procedures. The eleven patients with intraventricular cysts had craniotomies in order to excise the intraventricular cysts. Nine of these patients had cysts in the fourth ventricle and two had cysts in the third ventricle. During the period of observation three patients with hydrocephalus died with infection and thromboembolic complications. The three patients with large supratentorial cysts had a craniotomy to excise the large cysticerci. These parasites were of the race-

Table 1 Benign cerebral cysticercosis (20 patients)

\begin{tabular}{|c|c|c|c|c|c|}
\hline \multicolumn{2}{|c|}{ Type of cysticercosis } & \multirow{2}{*}{$\begin{array}{l}\text { Number } \\
9\end{array}$} & \multirow{2}{*}{$\begin{array}{l}\% \\
45\end{array}$} & \multicolumn{2}{|l|}{ Symptoms } \\
\hline 1. & Patients with parenchymal cysts & & & $\begin{array}{l}\text { Asymptomatic } \\
\text { Seizures } \\
\text { Headaches }\end{array}$ & $\begin{array}{l}1 / 9 \\
4 / 9 \\
4 / 9\end{array}$ \\
\hline 2. & Patients with calcified parasites & 2 & 10 & $\begin{array}{l}\text { Headaches } \\
\text { Seizures }\end{array}$ & $\begin{array}{l}1 / 2 \\
1 / 2\end{array}$ \\
\hline 3. & Patients with both parenchymal cysts and calcified parasites & 3 & 15 & $\begin{array}{l}\text { Asymptomatic } \\
\text { Seizures }\end{array}$ & $\begin{array}{l}2 / 3 \\
1 / 3\end{array}$ \\
\hline 4. & Patients with isolated granuloma & 2 & 10 & $\begin{array}{l}\text { Headaches } \\
\text { Seizures }\end{array}$ & $\begin{array}{l}1 / 2 \\
1 / 2\end{array}$ \\
\hline 5. & Patients with parenchymal cysts and isolated granuloma & 4 & 20 & $\begin{array}{l}\text { Headache } \\
\text { Seizures }\end{array}$ & $\begin{array}{l}2 / 4 \\
2 / 4\end{array}$ \\
\hline
\end{tabular}


Table 2 Results of ELISA in serum and CSF in malignant cerebral cysticercosis (31 patients)

\begin{tabular}{|c|c|c|c|c|}
\hline \multicolumn{2}{|c|}{ Type of cysticercosis } & \multirow{2}{*}{$\begin{array}{l}\text { Number } \\
26\end{array}$} & \multirow{2}{*}{$\begin{array}{l}\% \\
83 \cdot 8\end{array}$} & \multirow{2}{*}{$\begin{array}{l}\text { Symptoms } \\
\text { Raised intracranial pressure. Multiple } \\
\text { symptoms }\end{array}$} \\
\hline 1. & Total number of patients with hydrocephalus & & & \\
\hline 2. & Hydrocephalus due to basal arachnoiditis & 15 & $48 \cdot 3$ & $\begin{array}{l}\text { Raised intracranial pressure. Multiple } \\
\text { symptoms. Cranial nerve palsies }\end{array}$ \\
\hline 3. & Hydrocephalus due to intraventricular cysts & 11 & $35 \cdot 4$ & $\begin{array}{l}\text { Bruns' syndrome. Raised intracranial } \\
\text { pressure, intermittent }\end{array}$ \\
\hline 4. & $\begin{array}{l}\text { Multiple granulomata surrounded by oedema (cysticercus } \\
\text { encephalitis) }\end{array}$ & 1 & $3 \cdot 2$ & $\begin{array}{l}\text { Diffuse encephalopathy, seizures, } \\
\text { raised intracranial pressure }\end{array}$ \\
\hline 5. & $\begin{array}{l}\text { Cerebral vasculitis and infarction associated to } \\
\text { arachnoiditis, granulomata or parenchymal cysts }\end{array}$ & 1 & $3 \cdot 2$ & Stroke, seizures \\
\hline 6. & Large supratentorial cysts & 3 & $9 \cdot 6$ & $\begin{array}{l}\text { Increased intracranial pressure. } \\
\text { Hemisphere symptoms }\end{array}$ \\
\hline
\end{tabular}

Table 3

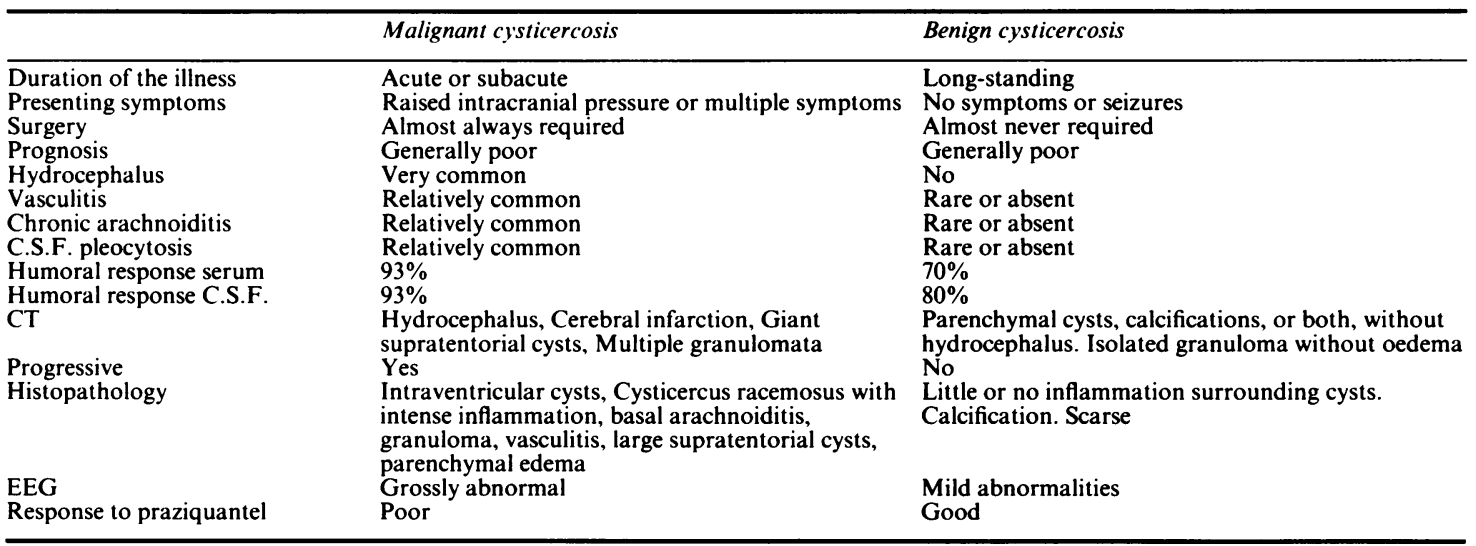

mous type and had large convoluted membranes. One patient had a cerebral infarction proven by CT. One patient had a diffuse encephalopathy with seizures and multiple granulomata surrounded by oedema. This patient responded to large doses of steroids. The usefulness of praziquantel therapy in patients with multiple granulomata surrounded by oedema is controversial. The patients with basal arachnoiditis were treated with oral prednisone at the dose of $50 \mathrm{mg}$ every other day during a six months period. Ten of these patients improved and the inflammatory cells in the CSF disappeared. Five patients had a persistant significant pleocytosis in the CSF. The ELISA test detected anticisticercus antibodies in $93 \%$ of the cases in the serum and in the CSF. This difference was significant statistically as compared with the benign group ( $\mathrm{p}<0.05$ using the $\chi^{2}$ method).

The EEG was grossly abnormal in these patients with presence of slow waves and epileptic foci. A summary and comparison of the findings in both groups is depicted in table 3.

\section{Discussion}

Cerebral cysticercosis is the most common parasitic infestation of the central nervous system in man and represents a serious health problem in many developing countries. Thus, a thorough knowledge of the heterogeneity of its clinical forms is of the utmost importance.

This study of a selected group of patients gives strong support to a previous evidence that cerebral cysticercosis may either be a benign or a malignant disease. The larger number of patients with malignant disease in our series in no way indicates that the malignant form is the more frequent or prevalent form the infestation. In fact, the pathological evidence shows that the benign forms are far more common. The greater number of malignant forms in our series is because these patients were seen in a third level neurological unit where the most complicated cases are sent for tertiary care. The management of patients with a benign form of cysticercosis is rela- 
tively simple and consists mainly in anticonvulsant therapy, analgesics and in some cases steroids. The advent of the new drug praziquantel seems to have simplified the management of patients with parenchymal cysts. ${ }^{912}$ It should be emphasised, however, that the usefulness of this drug in the calcified forms or in granuloma is debatable. On the other hand, if the parenchymal cysts are relatively benign the clinical usefulness of the drug seems to be worthy of future studies to compare the clinical course of patients with parenchymal cysts in a control trial with a longitudinal follow up. Pathological studies have shown that patients with round parenchymatous cysts of Cysticercus cellulosae type have little inflammatory reaction surrounding the cysts. ${ }^{23}$ There is now a good correlation between this histological picture and the clinical course, CT findings, and humoral response in patients with parenchymatous cysts. ${ }^{11}$

On the other hand, the malignant forms of cerebral cysticercosis are complex and heterogeneous. Hydrocephalus is the malignant form par excellence. It requires aggressive management that is not confined to a shunting procedure. The presence of an intraventricular parasite is suggested by the persistence of a dilated fourth or third ventricle after a shunt. The intraventricular parasite may be demonstrated by the instilation of contrast material through the antechamber of the shunt. The presence of an intraventricular parasite indicates an important risk of sudden death in case of malfunctioning of the shunting device and therefore a serious attempt to extract the parasite should be made whenever possible. ${ }^{6}$ The presence of subarachnoid blockage and inflammation should be sought deliberately after shunting through the intrathecal injection of an isotope. ${ }^{6}$ The presence of subarachnoid blockage along with significant pleocytosis in the CSF almost invariably indicates the presence of a chronic arachnoiditis. ${ }^{26} \mathrm{~A}$ chronic meningitis of cysticercus origin leads to vasculitis, cranial nerve palsies and probably brain stem damage. ${ }^{256}$ Many of these patients deteriorate despite adequate shunting procedures. ${ }^{6}$ There is no known effective therapy for this condition. We have used long-term steroid therapy but a control trial seems most warranted. Large supratentorial cysts in the Sylvian cysterns are best treated surgically usually with good results although sometimes several operations are required. The encephalitic form of cerebral cys- ticercosis is in our experience most frequent in children and has a great morbidity and mortality. From the pathogenetic point of view cerebral cysticercosis may induce symptoms either by mechanical compression or obstruction (for example intraventricular cysts, large supratentorial cysts) or by the production of an inflammatory process (for example basal arachnoiditis, vasculitis, granuloma with oedema formation). The physicians caring for these patients must carefully consider the mechanism of cerebral damage in order to provide a rational and effective therapy.

\section{References}

${ }^{1}$ Gardner B, Goldberg M, Heiner D. The natural history of parenchymal central nervous system cysticercosis. Neurology 1984;34, (Suppl 1):90.

${ }^{2}$ Rabiela MT, Rivas HA, Rodríguez IJ. Consideraciones anatomopatológicas sobre cisticercosis cerebral como causa de muerte. Patol México 1979;17:119.

${ }^{3}$ Showramma A, Reddy DB. Silent cysticercosis of the brain. An analysis of five cases with special reference to histopathology. Indian J Pathol Bacterol 1963;6:142.

${ }^{4}$ Bhaskaran CS. Cerebral cysticercosis as a cause of unnatural deaths. Indian J Med Sci 1973;27:545.

${ }^{5}$ Estañol B, Corona T, Abad P. Clasificación pronóstica de la cisticercosis cerebral. Implicaciones terapéuticas. Gaceta Médica de México (In press).

${ }^{6}$ Estañol B, Kleriga E, Lombardo L, Loyo M. Mechanisms of hydrocephalus in cerebral cysticercosis. Implications for therapy. Neurosurgery 1983;13:119.

${ }^{7}$ Flisser A, Woodhouse, Larralde L. Human cysticercosis; antigens, antibodies and non responders. Clin Exp Immunol 1980;39:27.

${ }^{8}$ Mohammad I, Heiner D, Miller B, Goldberg M, Kagan I. Enzyme-linked immunosorbent assay for the diagnosis of cerebral cysticercosis. J Clin Microbiol 1984;20:775.

${ }^{9}$ Lombardo L, Mateos JH. Cerebral cysticercosis in Mexico. Neurology 1961;11:824.

${ }^{10}$ Powell SJ, Protor EM, Wilmot AJ, Macleod IN. Cysticercosis and epilepsy in Africans: a clinical and serological study. Ann Trop Med Parasitol 1966;60:152.

${ }^{11}$ Corona T, Pascoe D, Estañol B, Landa L. Anticysticercous antibodies in serum and cerebrospinal fluid in patients with proven cerebral cysticercosis. $J$ Neurol Neurosurg Psychiatry (In press).

${ }^{12}$ Sotelo J, Escobedo F, Rodríguez J, Torres B, Rubio F. Therapy of parenchymal brain cysticercosis with praziquantel. N Engl J Med 1984;310:1001. 